\title{
Semantic Change in Urdu: A Case Study of "Mashkoor"
}

\author{
Saira Zahid \\ Government College University, Faisalabad, Pakistan \\ E-mail: sara.linguistics@gmail.com \\ Muhammad Asim Mahmood \\ Government College University, Faisalabad, Pakistan \\ E-mail: masimrai@gmail.com \\ Ansa Sattar \\ Government College University, Faisalabad, Pakistan \\ E-mail: ansa.appliedlinguistics@gmail.com
}

Received: August 1, 2011

Accepted: September 23, 2011

Published: February 1, 2012

doi:10.5539/ass.v8n2p164

URL: http://dx.doi.org/10.5539/ass.v8n2p164

\begin{abstract}
Languages are dynamic in nature and Urdu language is no exception. This study aims to probe semantic change in Urdu lexis and focuses on the meaning of the word "mashkoor" (thanked). For this study, Urdu dictionaries, a corpus of 25 million Urdu words and a questionnaire have been used. Our analysis determines that "mashkoor" has shifted meanings from being "thanked" to "thankful". The results depict that the grammarians, lexicographers or the teachers are not the authority to decide correct usage in a language but it is the prerogative of users as well. The present study strengthens the idea that Urdu language has changed with the passage of time. It also proposes that Urdu dictionaries should be corpus based and include the current usage by the masses to incorporate the latest changes. This study will serve for other researchers as a springboard to further explore the other aspects of Urdu language.
\end{abstract}

Keywords: Semantic change, Urdu language, User authority

\section{Introduction}

Living languages have a tendency to change over time. This change may be explained in phonetic, syntactic and semantic terms. New words, novel meanings, different pronunciations, deviant grammatical forms are continuously coming into use replacing the older ones. (Trask, 1994)

Like other aspects of language, the meanings of words also change constantly. The scholars are interested in change in the meanings of linguistic expressions and the spread of specific forms into new meanings. The meanings of words with the passage of time may become more positive or negative, may become broader or narrower, turn more specialized or generalized and may also employ metaphor or different kinds of metonymy. The meanings of different words in a language may perhaps be caused by the factors inside or outside the language (Campbell, 2004).

These factors cause different types of change in words' meanings. Many researchers have proposed different mechanisms or ways of classifying these changes. As Geeraerts (2009) distinguishes between semasiological and onomasiological mechanisms. Semasiological mechanism provides existing words with new meaning and onomasiological involves changes through which a concept comes to be expressed by a new item. The new meaning of words can replace or coexist with the older one. Traugott and Dasher (2002) state that the old meanings of the words do not need to disappear. New meanings can coexist with the older ones.

The older meanings of words cause the existence of new ones following the process of expansion or omission. Briefly, lexical semantic change may occur due to the expansion in context, e.g. the term "pool" has undergone a wide increase in distribution as this term is now being used in a number of contexts. The other cause of semantic 
change may be omission where elimination of one word leads to change in meanings of the other words. English word "undertaker" is an example. The preferred context for the word "undertaker" was "funeral undertaker" but later "funeral" was omitted (Lehmann, 1992).

As for the source of semantic change, Auroux (2006) states that the causes of semantic change may be divided into linguistic and extra-linguistic ones. According to www.crack.ru/catalog/db/4420.doc, the change in lexical meaning of the noun "pen" was because of the extra-linguistic causes. Primarily "pen" goes back to the Latin word "penna" (a feather of a bird) when people wrote with goose pens. The name was shifted to the steel pens which were later on used for writing. Conversely, the causes of semantic change can be linguistic too. The conflict of the synonyms is an example of linguistic causes. When a perfect synonym of a native word is borrowed from some other language one of them may have a specialized sense. The noun "tide" in Old English was polisemantic and was used in the meanings of "time", "season", and "hour". When English borrowed the French words "time", "season" and "hour" they ousted the word "tide" in these meanings. It used to be specialized but now means "regular rise and fall of sea caused by the attraction of moon". (p.2)

Furthermore, Croft (2000) proposes two stages of change: the innovation, referring to the first new usage and the propagation, referring to the spread of this change to the other members of the community (as cited in Lingvistkredsen, 2006). Traugott \& Dasher (2002) divide semantic change at macro and micro levels. At the micro-level each occurrence of semantic change has its own peculiar characteristics. Each lexeme is considered on its own in the light of its individual history. It may possibly derive from the specific properties of the lexeme undergoing change, from the broader lexical and grammatical system in a particular language. It may also be derived from the circumstances surrounding the actuation of the change in a community at particular time. However at the macro-level, the direction of semantic change is often predictable, not only within a language but also cross-linguistically.

All the above mentioned aspects of semantic change are discussed briefly by a number of scholars. Extensive work has been done on the change in meanings of different words of different languages. As Loureiro (2008) studies the lexical and semantic change in Old English (OE) and Middle English (ME) and analyzes the verb 'need' meaning 'force' in $\mathrm{OE}$ and 'need' meaning 'be necessary' in ME. He has used a corpus of 2.4 million-words of $\mathrm{OE}$ and ME to observe three factors: (1) relative frequency of both verbs in the two periods, (2) their syntactic properties, (3) and their semantic implications.

In the same way, Akimoto (2008) discusses the contention among the verbs of wanting (wish, desire, want and hope) from Middle English to present-day English. The findings of his research show that the functional and semantic expansion and reduction of these verbs over time leads to the reshuffling of system of these verbs of wanting. The verb 'desire' has reduced while 'want' has expanded its function with the passage of time.

Similarly, Biscetti (2008) has traced the history of the word 'bloody' from a holistic perspective and studied 'bloody' in relation to the other items inside the system of intensification. He suggests that it is the reformation of the possible socio-historical context where the adjective 'bloody' has become an intensifier and a taboo word.

All the above mentioned studies lead to the fact that all languages in the world change over time. Like other languages, Urdu has also changed with the passage of time. This research paper aims to find out the dimension of semantic change in Urdu, discussing how the linguistic expressions change their meanings over time. The researchers observed that Urdu speakers are using lexis in different senses from the meanings given in dictionaries. We have studied this phenomenon with reference to the word "mashkoor" (thanked) in Urdu. The meaning of the word "mashkoor" in earlier times was "thanked" but now it is observed that the Pakistani Urdu users are using it in a different sense. The researchers aim to explore the nature of this change.

\section{Methodology}

\subsection{Instrumentation}

We consulted dictionaries (Ferozul-lughaat Farsi part 2, kaomi Angrezi- Urdu Lughat, Ferozul-lughaat Urdu, Farhang-e-Aasfia part 4, Noor-ul-lughaat part 3) to get the meanings of the word "mashkoor" (thanked) as dictionaries are considered to be the ultimate authority for determining the accurate pronunciation and meanings of the words (Fromkin, Rodman \& Hyans, 2010).

We collected a corpus of 25 million words of Urdu from newspapers, books and articles penned by Pakistani writers. The corpus was then tagged and annotated with the help of software. Corpus is considered as important in semantic studies of languages because it "provides objective criteria for assessing meanings to linguistic items" (McEnery \& Wilson, 2001, p.112). 
We also designed a questionnaire to collect data from the Urdu speakers. We used questionnaire for collecting data because it is one of the most important research tools for data collection (Dornyei, 2010). For this purpose a sample of 80 students ( 40 males and 40 females) and 70 teachers (20 male, 20 female general teachers and 15 male, 15 female Urdu teachers) from Faisalabad has been randomly selected. The first part of the questionnaire is used to bring out personal information from the participants. The rest aims to get participants' opinion about the changeability of a language, the authority to decide correct meanings of a word in language, language users' role in semantic change and finally, the meaning of the word "mashkoor" as currently used in Urdu.

\subsection{Data Collection}

For the collection of data, the colleges and the participants were selected randomly. Teachers and students from Urdu, Sociology, Business and languages departments of Government College University Faisalabad, Punjaab College Jaranwala, Shiblee College, Government Degree College for Boys, Government Degree College for Women Chak Jhumra, Government College for Boys, Sammanabad, Government College for Women Madina Town and Islamia College for Women were selected randomly. The reason for selecting college students and teachers is that our target population is the educated users of Urdu and the teachers are believed to have expertise in their field. Gender, status and work experience of the respondents were also taken into account.

\subsection{Analysis}

The dictionaries have been consulted to find the meaning of the word "mashkoor". The meanings have been arranged into semantic categories and analyzed qualitatively. Furthermore, the Antconc software has been used to get the frequency of "mashkoor" from the collected corpus. The use of this word has been studied in various contexts to see in which sense this word is being used by the Urdu writers. The results obtained from the questionnaire have been analyzed on SPSS 19. The frequency of the teachers and students' responses has been analyzed with reference to the given questions. Gender, teacher and student status and their work experience based differences have also been studied by cross tabulation.

\section{Results}

The results of the study illustrate a clear picture of semantic change in Urdu language. The data collected from dictionaries highlights that the word "mashkoor" means "thanked" not "thankful" and it is the object or receiver not the subject or giver of gratitude. The consulted dictionary "Ferozul-lughaat Farsi part 2 (1962)" states that the meaning of the word "mashkoor" is "thanked" and the use of this word in the meanings of "thankful" is incorrect (p. 409). The dictionary Feroz-ul-lughaat Urdu (1964) provides the meaning of "mashkoor" as the person who receives gratitude (p. 1124). Similarly, the dictionary Farhang-e-Aasfia (1979) makes clear that the meaning of "mashkoor" is thanked and the usage of this word in the meanings of obliged or thankful is not acceptable (p. 359). Noor-ul-lughaat part 3 (1989) explains the required word in the same way stating that "mashkoor" means thanked not thankful (p. 1274). According to Feroz-ul-Lughaat Urdu (2007), the word "mashkoor" refers to the person who receives gratitude (p. 1314).

But on the basis of corpus based study, opposite use of its meaning has been observed. The corpus was collected from literary books, newspapers, and articles. The corpus provides examples of language as used by the professional authors and checked over by editors. Thus their linguistic usage gains sufficient authenticity. The word "mashkoor" has been used 116 times in the collected corpora, 115 times in the meaning of "thankful" and only once in the meaning of "thanked". This shows clearly that current Urdu speakers use "mashkoor" differently as compared to its usage in earlier times or in current dictionaries. For example the corpus consists of the sentences in which "mashkoor" is used in the context like "men ap ka tah-e-dil sy mashkoor hon" (I am obliged to you), "men ap ka mamnoon o mashkoor hon" (I am highly thankful to you).

The questionnaire used to collect teachers and learners' opinions also bolsters the results of corpus analysis.

1) Do languages change over time?

The results of the questionnaire show that almost all the respondents agree that languages tend to change over time. The data shows that 98.8 percent students, 79.2 percent general teachers and 100 percent Urdu teachers accept the semantic change as a regular feature of languages. These results are summarized in Table 1.

2) Who has the authority to decide the correct meaning of a word in language?

Having determined that change in language is a natural phenomenon, the next issue is attribution of authority to decide the correct meanings of a word in a language. The results of our data depict that the user of a language has the authority to decide the correct meanings in language instead of the grammarian, lexicographer or the 
teacher. As $46.3 \%$ students, $50 \%$ Urdu teachers and $41.7 \%$ general teachers agree that the user of language has the authority to decide the correct or incorrect form in a language (see Table 2).

3) Change in meaning from the speakers is acceptable in language.

$62.5 \%$ students, $66.7 \%$ general teachers and $70 \%$ Urdu teachers agree that the users can also bring changes in the meanings of words of a language, proving that "a language is defined by a community that uses it" (Posner, 1997, p.70). The results of this question are given in Table 3 .

4) Which translation of this sentence is correct: "I am thankful to you":

As far as the meaning of "mashkoor" is concerned, $87.5 \%$ students, $62.5 \%$ general teachers and $63 \%$ Urdu teachers translate this word as "thankful or thanks giver". Only $8.3 \%$ general teachers and $13 \%$ Urdu teachers translate it as "thanked, or thanks receiver" (see table.4). This shows that the present Urdu speakers have altered its meanings from "thanked" to "thankful" and are using it as a subject instead of object. Therefore, we can claim that Urdu language users have shifted the semantic and grammatical position of "mashkoor" (thanked) entirely.

5) What is the correct meaning of this sentence "men aap ka mashkoor hon" (you are thankful to me):

The present Urdu language speakers are using "mashkoor" in the meanings of "thankful" or as a synonym to "shukarguzaar". The data shows that $83.8 \%$ students, $64.6 \%$ general teachers and $60 \%$ Urdu teachers use the words "mashkoor" and "shukarguzaar" interchangeably (see Table 5).

6) Can these statements replace each other (1) Mein tumhara shukarguzaar hon (I am thankful to you) (2) Tm mery mashkoor ho (I am grateful to you)?

$86.3 \%$ students, $68.8 \%$ general teachers and $63 \%$ Urdu teachers disagree that the statements "Mein tumhara shukarguzaar hon" and "Tum mery mashkoor ho" can replace each other. They do not consider both the uses as interchangeable (Table 6).

7) Which of the following option is incorrect "Ap ny meri madad ki is liey men ap ka hon" (you helped me and for that I am to you):

Only $30 \%$ students, $27.10 \%$ general teachers and $16 \%$ Urdu teachers have marked the option "mashkoor" (thanked) as incorrect in the given context (given in Table 7). The results indicate that the users of Urdu language are using the words "mashkoor" and "shukarguzar" in the same meanings. No gender-based variation has been observed in this regard.

\section{Discussion}

Languages change with the passage of time as they are dynamic in nature. Urdu language has also undergone changes over time in its pronunciation, vocabulary, grammar as well as meanings. This research paper has come up with the argumentation that the meanings of words in Urdu have changed overtime. The results obtained from the dictionaries depict that the Urdu dictionaries are intuition based as they insist on providing traditional meaning of the word which is different from the current usage. This study suggests that the dictionaries should be corpus based so that the current use of forms in language can be codified.

After determining what the dictionary says about the meaning of "mashkoor" (thanked) the corpus and the questionnaires were used to see how the present users of Urdu are using this word. The results of corpus analysis show that the word "mashkoor" is being used in a different sense from that given in the dictionaries. The questionnaire was used to get information about the common people's usage of this word. Not only the general teachers and learners are using this word in the meaning of "thankful" but the Urdu teachers too are using it in the same sense. The Urdu teachers who are the specialists in their subject are using "mashkoor" in the meaning of "thankful". So the results obtained from the corpus and questionnaire depict that the present Urdu users are using this word in the meaning of "thankful". But the dictionary is providing opposite use of this word. The lexicographers should compile dictionaries based on corpus data and should not rely only on unscientific conjecture based means.

The analysis of the collected data and the results of questionnaire also substantiate the semantic change in Urdu language. Most of the respondents have accepted the dynamic nature of languages and agree that Urdu language has also changed. This change is manifested in the results of this study as we see that the word "mashkoor" (thanked) has changed its meanings with the passage of time. Not only the students and general teachers are using it in the meaning of "thankful", even the Urdu teachers and learners are using the word "mashkoor" in this sense. 
In general, the grammarians, lexicographers and the teachers are believed to have the authority to decide the correct structures, forms and meanings of words in a language. But the findings of our research do not confirm these assumptions. Pakistani Urdu users including the students, general teachers and the Urdu teachers argue that it is not the grammarians, lexicographers or the teachers who decides correct forms in a language but the users of a language have this authority. They can use any new or alternative lexical item or form in a language and it will be acceptable as part of a language because each language survives on the basis of its usage.

This research paper proposes to empower the users by recommending that teachers should accept this dynamic nature of languages and teach the new and current forms and structures to the learners. They should not compel students to consult dictionaries for each form and should not mark the current forms in language from students as incorrect. So, the correct usage of a form in language is not determined by dictionaries only. The forms used by the speakers of language must also be taken into account while determining the correct usage of a word. This study provides only one example of change of meaning in Urdu. There are several changes not only in the semantic field but also in the phonological and syntactic aspects of Urdu, which have undergone changes with the passage of time. Extensive work needs to be done on all these aspects of Urdu language.

\section{Conclusion}

The findings of our research illustrate that Urdu language has gone through change over time like French, English, Japanese and Sanskrit languages. This paper confirms the semantic change in Urdu with the passage of time. The present Urdu users including the students, general teachers and even the Urdu teachers are using the word "mashkoor" (thanked) in different context from that of the older Urdu usage. It has shifted its meanings from "thanked' to "thankful" and now is being used as a subject. This research paper argues that users of a language have the authority to determine the correct forms in a language and the lexicographers, grammarians and the teachers are not sole authorities in this regard. The Urdu speakers claim that the users of a language can bring changes in a language proving that the change in meaning from speakers is acceptable in language. This study also recommends the use of corpus for writing Urdu dictionaries.

\section{References}

Akimoto, M. (2008). Rivalry among the verbs of wanting. In Maurizio Gotti, Marina Dossenna, Richard Dury (Eds.). English Historical Linguistics 2006, Volume II: Lexical and Semantic Change. (pp. 117-138). John Benjamins Publishing Company.

Auroux, S. (2006). History of language sciences. Walter De Gruyter.

Biscetti, S. (2008). The diachronic development of the intensifier "bloody": A case study in historical pragmatics. In Maurizio Gotti, Marina Dossenna, Richard Dury (Eds.). English Historical Linguistics 2006, Volume II: Lexical and Semantic Change. (pp. 117-138). John Benjamins Publishing Company.

Campbell, L. (2004). Historical linguistics: an introduction ( $2^{\text {nd }}$ ed.). Edinburgh University Press.

Dehlvi, M. S. (Ed.) (1979). Farhang-e-Asfia. 4. Ashfaq Ahmad, Maktabah Hassan Sohail Limited.

Dornyei, Z. \& Taguchi, T. (2010). Queationnaires in second language research: construction, administration and processing $\left(2^{\text {nd }}\right.$ ed.). Taylor \& Francis.

Feroz-Ud-Din, M. (Ed.). (1962). Feroz_ul_lughaat farsi. 2. Feroz Sons Limited Lahore.

Feroz-ud-Din, M. (Ed.). (1964). Feroz-ul-lughaat Urdu. Feroz Sons Limited Lahore.

Feroz-ud-Din, M. (Ed.). (2005). Feroz-ul-Lughaat Urdu. Feroz Sons Limited Lahore.

Feroz-ud-Din, M. (Ed.). (2007). Feroz-ul-Lughaat Urdu. Feroz Sons Limited Lahore.

Fromkin, V., Rodman, R. \& Hyams, N. (2010). An introduction to language ( $9^{\text {th }}$ ed.). Cengage Learning.

Geeraerts, D. (2009). Theories of lexical semantics. Oxford University Press. http://dx.doi.org/10.1093/acprof:oso/9780198700302.001.0001

Jalbi, J. (Ed.). (2002). Koomi angrezi urdu lughat. Alhamra Publishing Islamabad.

Lehmann, W. P. (1992). Historical linguistics: An introduction ( $3^{\text {rd }}$ ed.). Routledge.

Lingvistkredsen. (2006). Acta linguistica hafniensia (Vol. 38). Nordisk Sprog- og Kulturforlag.

Loureiro-Porto, L. (2008). The convergence of two need verbs in Middle English. In Maurizio Gotti, Marina Dossenna, Richard Dury (Eds.). English historical linguistics 2006, Volume II: lexical and semantic change, 2, (pp. 97-116). 
McEnery, T. \& Wilson, A. (2001). Corpus linguistics: an introduction ( $2^{\text {nd }}$ ed.). A. Wilson, (Ed.). Edinburgh University Press.

Nayyar, M. N. H. (Ed.). (1989). Noor-ul-lughaat. Sang-e-mail Publications Lahore.

Posner, R. (1997). Linguistic change in French. Oxford University Press.

Semantic Change. (n.d.). [Online] Available: www.crack.ru/catalog/db/4420.doc.

Trask, R. L. (1994). Language change. Routledge.

Traugott, E. C. \& Dasher, R. B. (2002). Regularity in semantic change. Cambridge University Press.

Table 1. Change in language over time

\begin{tabular}{|c|l|c|c|}
\hline Sr. No. & \multicolumn{1}{|c|}{ Respondents } & Yes & No \\
\hline 1 & Students & $98.80 \%$ & $1.30 \%$ \\
\hline 2 & General teachers & $79.20 \%$ & $4.20 \%$ \\
\hline 3 & Urdu teachers & $100 \%$ & 0 \\
\hline
\end{tabular}

Table 2. Authority to decide correct forms in language

\begin{tabular}{|c|l|c|c|r|r|}
\hline Sr. No. & \multicolumn{1}{|c|}{ Respondents } & Grammarian & lexicographer & Teacher & \multicolumn{1}{|c|}{ language user } \\
\hline 1 & Students & $27.80 \%$ & $23.80 \%$ & $1.30 \%$ & $46.30 \%$ \\
\hline 2 & General teachers & $10.40 \%$ & $20.80 \%$ & $10.40 \%$ & $41.70 \%$ \\
\hline 3 & Urdu teachers & $16 \%$ & $23 \%$ & $10 \%$ & $50 \%$ \\
\hline
\end{tabular}

Table 3. Change in meaning from the speakers is acceptable

\begin{tabular}{|c|l|c|c|}
\hline Sr. No. & \multicolumn{1}{|c|}{ Respondents } & Correct & Incorrect \\
\hline 1 & Students & $62.00 \%$ & $37.50 \%$ \\
\hline 2 & General teachers & $66.70 \%$ & $14.60 \%$ \\
\hline 3 & Urdu teachers & $70 \%$ & $30 \%$ \\
\hline
\end{tabular}

Table 4. Correct translation of the sentence "I am thankful to you"

\begin{tabular}{|c|l|c|c|c|c|}
\hline Sr. No. & \multicolumn{1}{|c|}{ Respondents } & $\begin{array}{c}\text { You are grateful to } \\
\text { me }\end{array}$ & $\begin{array}{c}\text { You are thankful to } \\
\text { me }\end{array}$ & $\begin{array}{c}\text { I am obliged to } \\
\text { you }\end{array}$ & $\begin{array}{c}\text { none of } \\
\text { these }\end{array}$ \\
\hline 1 & Students & $87.50 \%$ & $3.80 \%$ & $0.00 \%$ & $8.80 \%$ \\
\hline 2 & General teachers & $62.50 \%$ & $4.20 \%$ & $8.30 \%$ & $8.30 \%$ \\
\hline 3 & Urdu teachers & $63 \%$ & $6 \%$ & $13 \%$ & $16 \%$ \\
\hline
\end{tabular}


Table 5. Correct meanings of the sentence "you are thankful to me"

\begin{tabular}{|c|l|c|c|c|c|}
\hline Sr. No. & \multicolumn{1}{|c|}{ Respondents } & I am grateful to you & $\begin{array}{c}\text { You are grateful to } \\
\text { me }\end{array}$ & 1 and 2 both & None of These \\
\hline 1 & Students & $83.80 \%$ & $5.00 \%$ & $3.80 \%$ & $7.50 \%$ \\
\hline 2 & General teachers & $64.60 \%$ & $14.60 \%$ & $0.00 \%$ & $4.20 \%$ \\
\hline 3 & Urdu teachers & $60 \%$ & $36 \%$ & $3 \%$ & $0 \%$ \\
\hline
\end{tabular}

Table 6. Replacement of these sentences "I am thankful to you" and "I am grateful to you"

\begin{tabular}{|c|c|c|c|}
\hline Sr. No. & Respondents & Yes & no \\
\hline 1 & Students & $13.80 \%$ & $86.30 \%$ \\
\hline 2 & General teachers & $14.60 \%$ & $68.80 \%$ \\
\hline 3 & Urdu teachers & $36 \%$ & $63 \%$ \\
\hline
\end{tabular}

Table 7. Incorrect usage of "thankful"

\begin{tabular}{|c|c|c|c|c|c|}
\hline $\begin{array}{c}\text { Sr. } \\
\text { No. }\end{array}$ & Respondents & Thanked & Obliged & Grateful & 2 and 3 both \\
\hline 1 & Students & $30.00 \%$ & $40.00 \%$ & $18.80 \%$ & $11.30 \%$ \\
\hline 2 & General teachers & $27.10 \%$ & $16.70 \%$ & $25 \%$ & $14.60 \%$ \\
\hline 3 & Urdu teachers & $16 \%$ & $33 \%$ & $36 \%$ & $13 \%$ \\
\hline
\end{tabular}

